Authors' Accepted Manuscript. Published as:

Miller, Kathleen A. and Valerie Belton, 2014. Water resource management and climate change adaptation: a holistic and multiple criteria perspective, Mitigation and Adaptation Strategies for Global Change, 19(3): 289-308. DOI 10.1007/s11027-013-9537-0

Available at: http://www.springerlink.com/openurl.asp?genre=article\&id=doi:10.1007/s11027-013-9537-0

\title{
Water resource management and climate change adaptation: a holistic and multiple criteria perspective
}

Kathleen A. Miller \& Valerie Belton

K. A. Miller $(*)$

Climate Science and Applications Program, Research Applications Lab, National Center for Atmospheric

Research, P.O. Box 3000, Boulder, CO 80307, USA

e-mail: kathleen@ucar.edu

V. Belton

Department of Management Science, University of Strathclyde, 40 George Street, Glasgow G1 1QE, UK

e-mail: val.belton@strath.ac.uk 
Abstract: Anthropogenic climate change is likely to significantly increase human exposure to droughts and floods. It will also alter seasonal patterns of water availability and affect water quality and the health of aquatic ecosystems with various implications for social and economic wellbeing. Policy development for water resource adaptation needs to allow for a holistic and transparent analysis of the probable consequences of policy options for the wide variety of water uses and users, and the existing ecosystem services associated with any stream basin. This paper puts forward an innovative methodological framework for planning development-compatible climate policies drawing on multi-criteria decision analysis and an implicit risk-management approach to the economics of climate change. Its objectives are to describe how the generic methodology could be tailored for analysis of long-range water planning and policy options in developing countries, and to describe the place of climate change considerations in water governance and planning processes. An experimental thought-exercise applying the methodology to water policy development in Yemen provides further insights on the complexity of water adaptation planning. It also highlights the value of conducting sensitivity analysis to explore the implications of multiple climate scenarios, and the importance of accounting for policy portfolios rather than individual policy options. Rather than constituting a tool that can generate clear measures of optimal solutions in the context of adaptation to uncertain climate futures, we find that this approach is best suited to supporting comprehensive and inclusive planning processes, where the focus is on finding socially acceptable paths forward.

Keywords: Water resource management; Adaptation policy; Climate change; Multi-criteria decision analysis; Droughts; Floods; Hydro-ecosystem impacts; Infrastructure planning; Risk management; Water allocation; Water system management; Climate economics 


\section{Introduction}

Profound changes in the global distribution of water availability, the intensity and duration of droughts and the frequency and magnitude of flooding events will be among the most immediate and significant effects of anthropogenic climate change. As the climate warms, there will be a general acceleration of the global water cycle, increasing the likelihood of both protracted dry spells and periods of very heavy precipitation (Allen and Ingram 2002; Dai 2006; Bates et al. 2008; Lenderink and Van Meijgaard 2008). Atmospheric circulation patterns also will change, causing storm tracks to shift in ways that cannot, as yet, be reliably forecast (Christensen et al. 2007). This will lead to potentially large, but difficult to predict, changes in regional runoff patterns and probabilities of hazardous weather events (Kundezewicz et al. 2007; Bates et al. 2008).

Such hydrologic changes pose considerable risks to human well-being and to the structure and functioning of water-dependent ecosystems. Adaptation will be required to reduce the potential for adverse impacts and to build resilience to potentially increased hydrologic variability. Adaptive water management practices, inclusive and well-informed planning processes, and well-conceived infrastructure projects could promote efficient and environmentally responsible use of available resources while reducing flood-related losses.

Here, we describe a methodological framework that can help governments to identify and implement an effective program for managing the water-related risks arising from a variable and changing climate. The framework was initially developed under the United Nations Environment Program (UNEP) MCA4climate (multi-criteria analysis for climate change) project (UNEP 2011). It is focused on planning development-compatible climate mitigation and adaptation policies. The methodology draws on multi-criteria decision analysis and an implicit riskmanagement approach to the economics of climate adaptation in order to evaluate the strengths 
and weaknesses of alternative policy choices across multiple performance criteria. This is to reflect a shift in economic thinking from a single-discipline focus on cost-benefit analysis to a new inter-disciplinary multi-dimensional risk analysis, particularly when applied to the climate change problem (e.g. Barker 2008).

This approach is meant to complement rather than replace other approaches to climaterelated policy and planning. Guidance on water resource adaptation planning is available from many other sources, and there are differences in focus, target audience, and suggested approaches across these sources. For example, the US Environmental Protection Agency has produced adaptation guidance material under its Climate Ready Water Utilities program and National Water Program (NDWAC 2011; USEPA 2012). Those reports, and similar reports for state and local agencies (NPCC 2010; Rosenzweig et al. 2011) have focused on articulating sound processes for on-going iterative adaptation planning.

For example, Major and O’Grady (2010) define an eight-step process for adaptation planning. The recommended process begins with identification of current and future climate hazards, followed by a sequence of activities to be taken by infrastructure planners to identify, prioritize, implement, monitor and revise projects to improve infrastructure resilience to climate hazards in New York City, New York, USA. Similar process advice is provided in other sources (e.g., National Research Council 2009). The International Institute for Sustainable Development (IISD) has collaborated with other institutions to develop a software tool and guidance manual to assist community-level adaptation planning in developing countries (IISD 2012). Their CRiSTAL tool consists of a step-by-step process for collaborative community planning efforts focused on identifying and reducing climate-related risks to livelihoods. 
The MCA4climate project differs from these other efforts by focusing not on the set of activities to be undertaken in planning for climate adaptation, but rather on a conceptual framework to be used within such a process. The intent of the approach is to facilitate systematic consideration of the consequences of alternative courses of action where the options under consideration are likely to have multiple effects. For example, an irrigation project typically would have impacts not only on crop yields and agricultural livelihoods in the project area, but also on the ecology of the source stream, water availability to downstream communities, and the quality of that water.

The aim of this paper is to formulate guidance on water policy applications of this multicriteria approach. We first discuss the nature of water policy problems in developing country contexts, and then explore how the generic MCA4climate criteria categories could be further elaborated for application to water resource adaptation policy assessment. We also describe an experimental exercise in which project participants thought through how the approach might be applied to the very difficult case of extreme water scarcity and limited institutional capacity in Yemen. That exercise highlighted the need to extend the analytical approach beyond simply comparing the performance of individual policy options to take into account inherent interactions among policies. For example, basic governance reforms, including clarification and enforcement of individual rights and responsibilities were found to be a prerequisite for adequate performance of many of the other options under consideration.

\section{Nature of water planning problems in a changing climate}

Water planning typically entails relatively long time scales, making it imperative to consider how climate and other key conditions might change over the planning horizon. The focus here will be 
on policies that explicitly address the anticipated impacts of climate change on water quantity, seasonal flow timing, drought and flood characteristics, and water quality, including impacts on water temperature, salinity, nutrient concentrations and silt transport. It is important that water resource policy makers take account of the limited predictability of future hydrologic conditions (Wilby and Dessai 2010; Yates and Miller 2011). We argue that planning and policy making should be conceived as promoting the selection of strategies that will be robust to the plausible range of future hydrologic change, while preserving both resilience to surprises and options to modify plans as the need arises. In this context, a strategy is judged to be robust if it will lead to an acceptable outcome across all anticipated scenarios, while a system would be considered to be resilient if its functionality could be quickly and easily restored after a disturbance (Groves et al. 2008a,b; Hallegatte 2009). Thus, the standards of robustness, resilience and flexibility should be kept in mind when applying and interpreting criteria for evaluating the merits of alternative adaptation options.

Water is a complex resource in that it plays a variety of roles in supporting human health, healthy ecosystems, and the production of food, energy, and transportation services. Water also provides important aesthetic, cultural and recreational values. These many uses and values are intertwined in ways that may result in both conflicts and synergies that need to be considered in any water planning process. Multi-criteria analysis methods are well suited to water policy problems because they facilitate balancing multiple objectives and assessing priorities among values that are often not easily monetized.

When developing water resource policies for climate change adaptation, it will be important to consider how climate change might alter the many potential externalities and interdependencies among different water uses and values in the region affected by the policy. For 
example, the risks to aquatic ecosystems resulting from the construction of urban water supply reservoirs might vary considerably depending upon the exact nature of changes in stream-flows, water temperatures and water quality. Similarly, the evaporative losses from a reservoir built to support hydropower production might have little impact on downstream water availability in a relatively cool and wet future climate, while they could substantially worsen low flows in a much hotter and drier future climate. In order to mitigate potentially adverse impacts, water planners should consider multiple climate scenarios when designing such projects.

In addition to planning for water infrastructure projects, the development of effective governance arrangements is an equally important part of the water policy portfolio. Institutions that define the ownership and nature of rights to use water and decision-making procedures for water project development may range from clearly codified national laws, to informal cooperative agreements, or to longstanding cultural practices. Policy initiatives designed to make governance more responsive to the challenges posed by climate change will need to start from the existing institutional foundation. It is important to recognize, for example, that national governments rarely have full decision making authority regarding water use and management. Rather, a wide variety of players ranging from individual farmers and domestic well owners to national water authorities make decisions regarding water use and management. The governance arrangements in place will determine lines of authority, rights and responsibilities, and the extent of coordination across these different levels of decision-making (Ostrom 2007; Meinzen-Dick 2007).

Many policy options are available to improve water resource management in ways that would help to maintain water quality and the reliable provision of water for human and ecological uses despite the impacts of climate change. Key steps in the planning process will be 
to establish priorities and to identify the most productive sequencing of policy interventions. The choice of appropriate policy options, as well as decisions on timing, sequencing and levels of investment will depend very much on the specific country context and the range of projected climate changes. For example, where water is already very scarce and the availability of water for domestic use is threatened by projected future drying, a nation may wish to focus policy development on protecting aquifers from premature depletion by unregulated irrigation and on improving the efficiency of urban water supply systems. Pursuit of those objectives would likely require investments in governance reform, supply infrastructure, monitoring capacity, improved irrigation techniques and pricing reforms. The overall problem of adaptation policy design can be conceived as constructing a portfolio of actions, and triggers for their implementation to best serve a country’s economic, fiscal, environmental, social, and institutional objectives.

In many cases, appropriate policy design will require basic information on the state of the water resource system, existing water use practices, hydrologic variability over time, and the status and sensitivity of water-dependent ecological resources. Thus, policies focused on building that information base would be good candidates for early investment and continued support.

\section{A multi-criteria approach to climate policy analysis}

By implementing a structured and transparent approach to policy development, governments will be able to better understand and assess how different climate change mitigation or adaptation policy options may affect their specific development objectives. Drawing on insights from a water resource management thought experiment focused on Yemen, this paper shows how the MCA4climate framework approach for planning pro-development climate policies can be a valuable part of the policy planning process. 
The MCA4climate approach was initially developed by UNEP with the aim of providing a generic analytical and practical framework to help governments identify climate policies and measures that are low cost, environmentally effective and consistent with national development goals (UNEP 2011). Systematic application of such a framework allows analysts to keep track of the strengths and weaknesses of policy alternatives across a broad set of performance criteria. This can help them to determine preferences among competing policy proposals, identify valuable synergies among policies, and set priorities for implementation.

The framework draws on multi-criteria decision analysis to support climate policy planning and incorporates a multi-tiered generic criteria tree. The latter was developed through a systematic consultative process involving leading experts in climate change mitigation and adaptation and informed by a range of relevant stakeholder perspectives. The generic multicriteria tree is designed to provide a structured representation of all concerns relevant to policy making in the areas of climate change mitigation and adaptation. The tree incorporates three levels, the first of which separates the criteria into inputs (i.e. the efforts required to implement) and outputs (i.e. the impacts of) the policy options to be evaluated. On the second level, inputs are subdivided into financing needs and implementation needs, and outputs are subdivided into five broad categories of impact (positive or negative); these second-level criteria are in turn decomposed to a greater level of detail at the third level of the tree which incorporates 19 criteria in total (Figure 1). These generic criteria can and need to be further tailored for application in any specific sector. The criteria tree, the main components of the MCA4climate methodological framework, and the economic principles underpinning this have all been described in detail in Scrieciu et al. paper of this Special Issue.

\section{[FIGURE 1 NEAR HERE]}


In order to meaningfully use this framework for evaluation of water resource adaptation policies and plans, it is necessary to customize the generic criteria tree, developing a tailored set of criteria and measurable indicators against which policy proposals can be assessed. Here, we will describe a set of criteria and indicators, aligned with the three-layered structure of the criteria tree referred to above, that could be used for water resource adaptation policy analysis. These should be viewed as a (non-exhaustive) package, which can be adapted to the specific situation being assessed.

As previously noted, there are deep uncertainties about local-level hydroclimatic changes as well as about such variables as population growth and technological change. This suggests that the best practice for using the MCA4climate framework would entail analysis of policy performance under a wide range of possible future scenarios. This would allow decision makers to evaluate options on the basis of their robustness, and help them to avoid policy choices that they would later regret. Specifically, an option that performs well (in terms of the criteria) under the full range of scenarios should be preferred over other competing options displaying poor performance for some scenarios, or for which performance is highly sensitive to the specific scenario. This implies that the policy must make sense even if the climate were to remain unchanged. By requiring that a policy pass the current-climate sensibility test, citizens can be assured that policy makers will not be able to use the prospect of future climate change to justify projects that otherwise would fail the current evaluation process.

Resilience (ability to recovery quickly from the effects of extreme events) and flexibility (ease of adjustment to evolving changes and new information) are additional desirable characteristics in the context of uncertainty. Policy options that focus on reducing social and 
environmental vulnerabilities to anticipated climate changes are likely to display robustness, resilience and flexibility. These characteristics are reflected in the set of descriptors discussed below.

\subsection{Inputs/ Public financing needs}

\subsubsection{Minimize spending on technology}

Adaptation in the water resource sector could entail a wide range of infrastructure investments including large capital-intensive projects such as major dams, reservoirs and canal systems, as well as modest rainwater harvesting systems built with local labor and requiring little in the way of technology expenditures. The important consideration will be expenditures per unit of improved performance. For example, if the goal is to increase the reliable yield of a waterresource system, an appropriate metric would be capital cost per unit of increased yield. Another possible indicator might be capital cost per unit area protected from floods of various specified magnitudes. Flexibility can be enhanced by instituting planning processes to identify low-cost improvements that can be quickly implemented as needed, and that pose little risk of interfering with future ecosystem services or with larger long-term projects that might become desirable in an altered future climate.

\subsubsection{Minimize other types of spending}

Other adaptation options may require improved documentation and enforcement of water rights, enhanced stream-system and aquifer observations, and additional monitoring and analysis of aquatic ecosystems. Descriptors of the monetary considerations associated with those adaptations include costs necessary to: a) draft and implement any new legislation needed to define rights, obligations and roles of public and private actors b) provide adequate enforcement for water rights to prevent illicit water diversions, and c) establish programs for making observations and 
for data storage and analysis. Appropriate levels of spending will depend on the severity of problems that would likely arise in the absence of the policy innovation. For example, investments in documenting and enforcing water rights will be more beneficial where there is intense competition for access to scarce water supplies than in settings with abundant water and sparse populations.

\subsection{Inputs/Implementation barriers}

\subsubsection{Allow for easy implementation}

Water policy development is often highly contentious, largely because the multiple interconnections previously described make it very difficult to implement changes without causing potential losses for at least some stakeholders. Open policy processes that provide meaningful opportunities for resolution of conflicting interests would facilitate progress with respect to this criterion. Metrics may be somewhat problematic because such open policy processes are likely to be messy and time-consuming in contrast to more authoritarian processes that ignore or suppress dissenting views. Thus a simple metric of feasibility based on the effort required to plan and implement an adaptation, would not be a good indicator of performance. A better descriptor might be provided by a qualitative assessment of whether or not processes and legal protections are in place to ensure fair consideration of all interests.

\subsubsection{Comply with required timing of policy intervention}

In the context of climate change adaptation, it is important to consider the time path of such investments relative to evolving information about the local-scale hydrologic impacts of climate change. In some cases, it may be possible to identify a logical sequence of investments and/or supportive policy changes that can be implemented in stages. Such a modular approach would 
enhance flexibility by allowing the timing of the stages to be accelerated or slowed down as warranted by evolving climatic conditions. Good performance with respect to this criterion would be exemplified by the existence of open on-going planning processes that are focused on developing such modular plans, tracking their progress and changing course as needed. The existence of such a process is suggested as the indicator for this criterion.

\subsection{Outputs/Climate-related}

\subsubsection{Reduce greenhouse gas and black carbon emissions}

The use of fossil fuels to pump, treat, and deliver water; heat water for washing and bathing; and treat sewerage results in significant greenhouse gas emissions (and in some cases, black carbon). Many of these functions could make use of renewable energy sources, such as wind and solar power. Sewerage treatment works also could be at least partially fuelled by on-site production of biogas. In addition, hydropower production could offset some fossil-fuel use, although further development of on-stream hydropower plants could lead to unwanted environmental impacts. Off-stream hydropower generation plants that use pump-back storage to produce valuable peakperiod electricity show promise as a complement to variable solar and wind-powered electric generation. There also may be opportunities to generate hydropower with water that is flowing by gravity through delivery systems. Useful indicators of progress with respect to this criterion would include the proportion of national electricity generation coming from renewable hydropower, wind, solar and biogas sources, and improvements in the energy efficiency of water supply services.

\subsubsection{Enhance resilience to climate change}


Resilience means the ability of a system to recover full functionality quickly after a disturbance. For example, an urban water supply system would be considered to be resilient if it could quickly (and at low cost) resume deliveries of safe drinking water despite disruption caused by flooding or pollution pulses related to heavy storm runoff. Given the potential for increases in the length of dry spells and periods of intense rainfall and high runoff, useful resilience descriptors would include measures of the diversity of water supply sources to serve critical uses such as urban water supplies, the capacity to store water (in both surface reservoirs and in groundwater systems), and the ability to limit flood-related damages, including siltation of reservoirs and water conveyance channels. Regarding diversity of water sources, urban water supply security can be enhanced by providing redundancy. Examples include maintaining more than one water treatment plant, connections to more than one source area, and coupling surface and groundwater supplies, with their inherently different response times to precipitation variability.

Watershed conditions, irrigation infrastructure development, settlement patterns and the extent of levees, dams and other control works will play a large role in driving the impacts of extreme drought and flood events. Adaptation actions in the agricultural, forestry and urban planning sectors will thus interact with water system adaptations in building resilience to climate change. Resilience, as described here obviously interacts with other criteria, such as the environmental, economic, and health criteria described below. So care must be taken to avoid double counting, but if one conceives of resilience as a characteristic of the system that provides insurance against disruption and facilitates quick recovery, it can be useful as a separate criterion for evaluating adaptation options.

\subsection{Outputs/Economic}




\subsubsection{Trigger private investment}

Here, the focus should be on stimulating investments that improve the capacity of individuals, businesses and communities to thrive despite changes in water availability or potential flooding. Examples might include policies rewarding private investments in flood retention ponds, groundwater recharge facilities, or riparian habitat protection, either through tax breaks or rights to recharged water. The existence of such policies would indicate good performance on this criterion. Options to avoid include subsidies that would stimulate investments in unsustainable groundwater pumping. To estimate the private investment impacts of public infrastructure projects designed for climate change adaptation, one might develop estimates, both with and without the project, based on measures of the market value of private investments stimulated by previous flood control or water supply projects.

\subsubsection{Improve economic performance}

Here, the focus is on economy-wide performance including changes in productivity and trade flows. Economy-wide productivity can be enhanced by policies that encourage efficient water use and cost-effective methods to produce and deliver water. In addition, avoidance of disasterrelated losses would improve overall economic performance if the costs incurred to avoid the losses are smaller than the avoided damages. The existence of planning processes that are actively considering climate-change related risks would indicate good performance on this criterion. A further indicator would be the estimated change in damages in terms of the value of economic activity directly and indirectly affected by water-related disasters relative to expenditures on project infrastructure.

\subsubsection{Generate employment}

Capital construction projects will increase employment during the planning and construction phase, but those jobs are typically temporary. Investments like new irrigation projects could 
produce long term employment gains, but this may entail some redistribution of labor from other areas and sectors. Estimates of net employment impacts should account for such movements, and should attempt to document changes in earnings created by the new direct and indirect employment opportunities associated with the project.

\subsubsection{Contribute to fiscal sustainability}

The fiscal impacts of a water infrastructure project might be estimated as the increase in public revenues from hook-up fees, property tax collections and sale of water to households and other municipal users relative to public expenditures for providing service improvements. Other policies that promote compliance with tax policies also would enhance fiscal sustainability.

\subsection{Outputs/Environmental}

\subsubsection{Protect environmental resources (quality and stocks)}

Some water management policies can adversely affect the stock of water available for maintaining environmental resources and supporting future water uses. For example, policies that encourage pumping of groundwater for agricultural use may lead to rapidly declining aquifer levels unless withdrawal rights are limited to the aquifer’s sustainable yield. Similarly, irrigators located in the upper reaches of a watershed might deplete stream water to the detriment of downstream water users and ecosystems unless their withdrawal rights are appropriately limited. Regarding water quality impacts, practices such as releasing untreated or poorly-treated sewerage and industrial wastes into natural water bodies are an obvious source of harm. Harm to water quality also can result from failure to control farming and grazing within riparian zones. Indicators of performance would include changes in standard metrics of water quality and changes in average and minimum streamflows or aquifer levels. 


\subsubsection{Protect biodiversity}

Past water project development has often damaged aquatic ecosystems and the diversity of species they support (World Commission on Dams 2000; Palmer 2010; Vörösmarty et al. 2010). Impacts include reduced streamflows, higher water temperatures, destruction of stream and riparian habitats, creation of unnatural flow regimes, and blocked access to river reaches needed to sustain migratory species (Graf 1999; Postel and Richter 2003). Climate change is likely to exacerbate those stresses (Bates et al. 2008). Governments could improve performance on this criterion by requiring changes in project design to avoid or offset biodiversity loss, and by regulating the operation of water control facilities to protect these resources. In addition, welldesigned and managed off-stream reservoirs, groundwater recharge schemes, and runoff-control systems can provide the capacity to improve stream conditions for aquatic biota while also enhancing water supply security and flood protection for human communities (Molden 2007). Therefore, the existence of programs to promote such conjunctive water management and floodmanagement systems would also indicate progress on this front. Countries can seek assistance in tracking the status of their biological resources from international environmental monitoring programs such as: the International Geosphere-Biosphere Program (IGBP) http://igbp.net/; DIVERSITAS http://www.diversitas-international.org/?page=about; and the Global Earth Observation Biodiversity Observation Network (GEO BON) http://www.earthobservations.org/geobon_a.shtml.

\subsubsection{Support ecosystem services}

Among the ecosystem services provided by water are provisioning services for direct human consumption, other household, municipal and industrial uses, and agricultural production. Water also provides: regulatory services, which include assimilating and transporting wastes; supporting services for fish and wildlife habitat, recreational amenities, and water-borne 
transportation; and cultural services, which support aesthetic and religious values. Given the large variety of these ecosystem services, it is difficult to identify simple descriptors of performance. Rather, direct measures of changes in each category of water use and measures of aquatic and riparian biodiversity could be used as performance metrics. Engagement with the newly-created Intergovernmental Science-Policy Platform on Biodiversity and Ecosystem Services (IPBES) http://www.ipbes.net/ may assist countries in monitoring ecosystem services and in designing appropriate actions to counter signs of degradation.

\subsection{Outputs/Social}

\subsubsection{Reduce poverty incidence}

Inadequate water availability can affect poverty incidence directly, as would be the case when a severe drought causes farmers without access to irrigation water to fall into poverty. Poor water supplies also can create poverty indirectly, as would be the case if employment opportunities are limited by the reluctance of industries to invest in a country because of unreliable service or poor quality water. Furthermore, many poor households in developing countries spend a sizable fraction of their household income, and/or substantial labor time to acquire water for drinking, cooking and bathing. The labor burden typically falls most heavily on women and children. The money and time spent to obtain water reduce a family's other consumption and/or employment options. Thus standard measures of income poverty would only capture part of the water/poverty problem. Two descriptors are useful here: 1) Income poverty, which could be measured by changes in average household income, the number of poor below a poverty line and/or the percent of household income devoted to water purchases; 2) Access poverty, which could be captured by measures of per capita domestic use of clean water, and the proportion of the 
population with access to treated, piped water or other high-quality potable water, together with information on reliability of service and cost (in money, time and effort).

\subsubsection{Reduce inequity}

Water policies and development projects have the potential to either reduce or increase inequities. For example, an irrigation project or urban water project that substantially reduces water costs for poor households would lead to greater equity, while projects or policies that only benefit large landowners or wealthy neighborhoods would have the opposite effect. Large water projects have often led to inequities when communities have been displaced or deprived of their livelihoods without adequate compensation from the project beneficiaries (see e.g. Pearce 2006). Descriptors of progress on reducing inequity would include changes in: the distribution of household income (market and non-market); wealth distribution; the proportion of household income devoted to water purchases; and impacts of water projects on displaced persons and communities.

Gender equity is another important issue, especially in some developing countries where women account for well over half of the agricultural workforce and are typically also responsible for domestic water use and irrigation of garden plots important both for family nutrition and market income (Faurès et al. 2007). Measures of impact on gender equity could include: formal membership of women in water user associations, and ease of access to water for domestic and garden use, perhaps measured by average distance to source and time spent hauling water.

\subsubsection{Improve health}

Protection of water quality and improved water access can reduce the incidence of several waterborne diseases. Well-designed irrigation projects and better on-farm water management can increase crop output, reduce food costs, and improve nutrition. On the other hand, poor water 
project management and design can contribute to increased health risks from diseases transmitted by mosquitoes (family Culicidae: Anopheles spp., Aedes spp., Culex spp.) and other waterdependent disease vectors. Descriptors of progress would include changes in disease incidence, improved nutritional status, reductions in the release of untreated sewerage into the environment, and reductions in the presence of pathogens and dangerous pollutants in water sources.

\subsubsection{Preserve cultural heritage}

The cultural heritage impacts of water policies and projects could include physical damages to tangible items such as archaeological sites, as well as impacts on cultural traditions including traditional methods of apportioning water and organizing community labor to maintain shared infrastructure such as terraces, canal systems and water tanks. Indicators of good performance would include the existence of provisions for protection or relocation of tangible cultural heritage resources prior to the construction of new water projects, and the extent to which the water planning process seeks to identify and build upon the strengths of pre-existing water management traditions and social relations.

\subsection{Outputs/Political and Institutional}

\subsubsection{Contribute to political stability}

Increasing conflicts could arise if climate change leads to deteriorating water availability. Conflict would be especially likely if the burden of reduced availability is not equally shared, and if the disproportionate pain is widely perceived to be unfair, or resulting from corruption or illicit appropriation of communal resources. Instability also might arise if increased flooding impoverishes some households or communities and little public assistance is provided to avert the disasters or assist recovery. Thus, policies that anticipate and minimize such uneven impacts 
would contribute to political stability. In addition, water planning and disaster risk management processes that are seen as open and equitable will promote political stability.

\subsubsection{Improve governance}

Good governance could be measured by the extent to which decisions regarding water allocation and development result from a process that balances public and private interests to ensure that sufficient water is allocated to the most valuable uses (e.g. basic human consumption and sanitation) and that waste is avoided. Water resource management is an arena in which defining clear and balanced roles for representatives of the central government, local collective interests and market forces could lead to better long-term outcomes in terms of reduced conflict and progress toward social, environmental and economic goals. Indicators could include the existence of formal mechanisms for multi-level coordination on planning and policy, and evidence that water marketing or another reallocation mechanism has operated to move water to more valuable uses without harming individuals who were not directly involved in the exchange.

\section{Case study: water resources in the Sana'a Basin, Yemen}

To examine the potential utility of the MCA4climate framework in a difficult and complex water policy setting and to inform its development, the project team developed an illustrative application of the framework to evaluate water resource policy options in Yemen’s Sana'a Basin. One purpose of the exercise was to inform the selection of criteria to be used for policy analysis. We were thus working with an earlier version of the criteria tree than that described above. In addition, this thought-experiment was constrained by limited data availability and scope of the exercise, as described in the case study report on the MCA4climate (UNEP 2011) project website. However, it was expected and served to highlight two things, namely: the potential 
added value and the associated complexity of extending a simple analysis of policy alternatives to incorporate consideration of multiple climate change scenarios; and the importance of taking into account the synergies (or otherwise) between evaluated options.

It was known at the start of the work on this case study that the impacts of the adaptation options available to policy makers would not be independent of one another. This became clearer as the work progressed. In particular, the analysis concluded that the presence or absence of governance reforms would have significant impacts on behavioral responses to other policy options, and therefore on their effectiveness.

Yemen is the poorest country in the Arab World and faces severe water scarcity, with nationwide renewable annual water availability estimated to be on the order of $140 \mathrm{~m}^{3}$ per capita, far below the World Health Organization's 1,000 $\mathrm{m}^{3}$ per capita threshold for high water scarcity (World Bank 2010; UN-OCHA 2012). Irrigated agriculture accounts for approximately 90 percent of Yemen's water consumption, but rather than providing food security, much of this water is used to grow the narcotic crop, qat (The Guardian 2010; UN-OCHA 2012). Yemen has a rich history of coping with limited water supplies, including a traditional system of terraces and spate check dams together with local water allocation institutions governing rights to springs and sporadic spate flows, but the traditional systems and practices have been severely challenged by modern expansion of groundwater pumping and by the water demands of a growing population.

The Sana'a Basin contains both extensive irrigated agriculture and the rapidly growing capital city, for which water and sanitation services are woefully inadequate. There has been rapid depletion of the Basin's limited groundwater resources, largely as a result of the explosive growth of groundwater pumping for irrigated agriculture that followed the introduction of diesel pumps in the 1970s, together with a government policy that heavily subsidized diesel prices. The 
resulting agricultural boom led to alarming drops in aquifer levels and loss of springs that formerly provided critical community water supplies. In response to the growing water crisis, the central government eventually reduced fuel subsidies and launched a program of legal reforms to constrain further expansion of groundwater use, but the status of those reforms is unclear given the current state of political turmoil in that nation.

Our hypothetical assessment was carried out in 2010, prior to Yemen’s current crisis, and the results reflect an expectation that while the weakness of the central government might impede policy development, progress was still possible. The past few years of conflict, however, have led to significant deterioration in the condition of water supply systems and in the population's access to safe drinking water (UN-OCHA 2012). The results of our analysis would likely differ if we repeated the exercise under current conditions. Nonetheless, the experiment does provide useful insights on the applicability of the analytical framework to water resource adaptation planning, and in particular, on the significance of interdependence among policy options as well as the sensitivity of policy preferences to assumptions about future climate.

In selecting policy options for analysis, the team reasoned that climate change appears likely to exacerbate an already worsening water crisis in the Sana'a Basin. Any climate adaptation options would, therefore, need to reinforce efforts to address the on-going overexploitation of groundwater resources. The major difference is that we would propose a more rapid and larger effort for each option than might be planned in the absence of the prospect of climate change.

We selected a set of eight options for analysis, including three basin-wide options (BW1, BW2 and BW3); three focused on the urban water sector (U1, U2 and U3) and two focused on 
rural agricultural water use (R1 and R2). Some of these are actually packages of measures that would be implemented together. These adaptation options are described in Table 1.

\section{[TABLE 1 NEAR HERE]}

Given the limited nature of the thought experiment, the study considered only two climate-change scenarios prepared by the World Bank (2010): a mid-range scenario with moderate warming (an increase of $3.1^{\circ}$ Celsius over 1990 levels by the 2080s) and small precipitation changes ( $3 \%$ fall); and a hot-dry scenario with amplified warming $\left(+4.5^{\circ} \mathrm{C}\right)$ and significant declines in precipitation (-24\%) resulting in major reductions in runoff and recharge.

At this stage the initial structuring of the decision problem was complete; the criteria tree had been contextualized in the specific context of water resource planning, options for evaluation specified and future climate change scenarios for consideration defined. The next step was to evaluate, or score, the identified options using a well-specified approach that is widely used in multi-attribute value analysis (Belton and Stewart 2002), which is also the main multi-criteria decision method incorporated in the MCA4climate framework. This is a process of direct rating on a 0 to 100 locally-defined preference scale. The scale for each criterion is anchored at the ends by the most and least preferred options on that criterion, with the most preferred option assigned a preference score of 100, and the least attractive a score of zero. Scores are assigned to the remaining options to reflect their performance relative to the two reference points, a process which can be informed by quantitative data, where available, but at other times must be based expert judgment. Drawing upon a review of the available literature, participants in the exercise were asked to score the 8 options against each of the criteria at the third level of the tree. At this stage the options were considered individually and independently, assuming no synergies or negative interactions between them. 
Discussion of these initial evaluations highlighted the fact that many of the other options would perform poorly in the absence of governance reforms. In particular, the governance reforms embodied in option BW1 would likely alter behavioral responses to the other policy options by clarifying who has the right to use water, the quantitative limits on the use rights, and the locus of decision-making authority to modify use rights. The reforms also would create enforcement mechanisms to ensure compliance with legally-defined rights and obligations. Similarly, monitoring systems are a necessary component of any water management program.

As a result, the project team conducted a second round of scoring in which it was assumed that basic physical monitoring systems which were implicit in the original specification of BW1 would be in place (even where they are currently inadequate) when scoring all the options and that the monitoring of water use and activities that could jeopardize water quality would occur as part of the package of governance reforms which constitute option BW1. The performance of each of the re-defined eight options was then evaluated with respect to the four input and fourteen output criteria defined above, in the context of each of the two specified climate scenarios.

Following on from the revision of scores, the initial analysis simply reflected back the allocated scores in a visual representation which facilitates comparison of the performance of options within and across the two scenarios. An illustration of this initial analysis (for ease of viewing this shows only 3 of the options) can be seen in Figures 2a and 2b, in which each criterion is represented by a vertical line (with the first four criteria from the left corresponding to the four input criteria at level three of the criteria tree, then moving on to the outputs in the order they appeared in the early version of the tree) and the performance profile of each option is depicted by a solid, dashed, or dotted line. A high score is preferred across both inputs and 
outputs and it can be seen that there is no option which performs strongly across all the criteria in either scenario. Of particular note is that the second basin-wide option (BW2) performs very poorly in the dry scenario, requiring a high level of input only to generate consistently low outputs in comparison to the other options.

\section{[FIGURES 2a; 2b NEAR HERE]}

The next stage of the analysis required the specification of criteria weights to enable the evaluations of the options to be aggregated to higher levels of the criteria tree. The specification of these weights, which capture the perceived relative added value of an increase from 0 to 100 on each scale, is a more cognitively challenging exercise and one which calls for the exercise of judgment. Furthermore, different stakeholders can be expected to have different views on the relative value of the different inputs and outputs. Hence, it is particularly important to explore the sensitivity of the aggregate evaluations to changes in the weights.

\section{[FIGURE 3 NEAR HERE]}

The process of specifying the scores and weights generated considerable discussion as participants attempted to articulate their reasons for allocating particular values, highlighting that a key benefit of the MCA4climate approach and MCDA more generally is its ability to spur such structured and focused discussions of what matters and why. An illustrative set of allocated weights is shown in Figure 3. The results derived from these, when combined with the allocated scores for the mid-range scenario and aggregated to the level of Inputs and Outputs, can be seen in Figure 4a, The aggregated scores are shown in two forms, as profile (line) graph and as an efficiency (XY) plot. The profile graph shows clearly that those options which have higher scores on Inputs (i.e. require less resource) tend to perform less well on Outputs (i.e. have lower impact) as would be expected in general. The efficiency plot makes clear which options make 
most effective use of the required Inputs in generating Outputs. The line joining options R2 and BW1 denotes the efficiency frontier, indicating that these options provide the greatest aggregate outputs in relation to their required inputs. For example, option U1, U2 and BW2 have lower input scores (ie require greater resources) than BW1 and also have lower impact (reflected in their lower output scores). Similarly, in comparison with R2 all options have lower input scores (so require greater resources), and all except for BW1 and U1 have lower output scores. In particular, BW2 and U2 have particularly low levels of output in relation to the input required.

\section{[FIGURES 4a AND 4b NEAR HERE]}

As the analysis was illustrative it was not known how the stakeholder groups would weight criteria, however, sensitivity analysis showed that options R2 and BW1 are robust to significant changes in the weights allocated to the sub-criteria of inputs and outputs. Other options move to the efficient frontier as the weight allocated to criteria changes; for example, option U3 performs well if Social impacts are more heavily weighted, as shown in Figure 4b.

Although the analysis of performance of the independent options was informative, in practice policy makers would likely wish to identify an effective portfolio of two or more options necessitating the consideration of potential synergies and negative interactions. In order to further explore this, all possible portfolios of one or more options (255 in total) were generated and their performances determined, first without consideration of potential positive or negative interactions (using a simple additive aggregation of individual performances) and secondly using a simple formula to reflect the anticipated synergy that would occur if options BW1and BW2 were both present in a portfolio. While this portfolio-comparison exercise was still a highly simplified experiment, it highlighted the increased complexity of seeking to model interactions and the likely sensitivity of the size and composition of the preferred policy portfolio to the 
nature of these interactions, as well as the level of resources (inputs) available for policy implementation, the assumed climate scenario and the weights assigned to criteria. This further emphasized the value of an interactive model which facilitated the exploration of different assumptions and acted as a catalyst for discussion and learning about the problem and different perspectives on it.

\section{Conclusion}

The comments and case analysis presented above indicate that the MCA4climate framework can help policy makers to think systematically about the wide range of water resource policy options available to them for responding to the potential impacts of climate change. We have argued that when considering how to improve water policy to facilitate adaptation to climate change, it is important to take a whole-system perspective that takes account of the various values, vulnerabilities and ecosystem services that a policy may affect. In addition, it is important to take account of the likely interactions among policy options in order to identify both the most desirable portfolio of actions and appropriate triggers for their implementation.

Where possible, analysts should evaluate the sensitivity of policy performance to different sets of assumed values for projected socioeconomic and climatic variables. This will allow an assessment of policy robustness in the face of inevitable uncertainties. If a proposed policy would perform poorly under some combinations of assumptions, further steps in the analysis would be to identify causes and potential remedies for the poor performance and then to redesign and retest the modified policy option. Ideally, policy makers should use the MCA4climate approach in an ongoing iterative planning process that would allow them to identify the most productive sequencing of policy interventions and to make adjustments as conditions change and new information becomes available. 


\section{Acknowledgement:}

The authors would like to acknowledge the valuable input provided by Sophy Bristow, ECN,

The Netherlands to this paper, and the helpful comments provided by Dr. Raghuram

Murtugudde, University of Maryland, and Dr. Chu Thai Hoanh, International Water

Management Institute, Laos to the initial report and related work carried out as part of UNEP's

MCA4climate initiative. The authors also acknowledge the financial and technical support from

UNEP and Government of Spain that they have received particularly during the conceptual phase

of the MCA4climate initiative, from which this paper derives. 


\section{References:}

Allen MR, Ingram, WJ (2002) Constraints on Future Changes in Climate and the Hydrologic Cycle. Nature 51(9):735-751

Barker T (2008) The economics of avoiding dangerous climate change. An editorial essay on The Stern Review. Climatic Change 89 (3-4): 173-194

Bates BC Kundzewicz ZW, Wu S, Palutikof JP (eds.) (2008) Climate Change and Water. Technical Paper of the Intergovernmental Panel on Climate Change, IPCC Secretariat, Geneva, Available at: http://www.ipcc.ch/pdf/technical-papers/climate-change-wateren.pdf

Belton V, Stewart TJ (2002) Multiple Criteria Decision Analysis: an Integrated Approach, Kluwer, Massachusetts

Christensen JH et al (2007) Regional Climate Projections. In: Solomon S et al (eds) Climate Change 2007: The Physical Science Basis. Contribution of Working Group I to the Fourth Assessment Report of the Intergovernmental Panel on Climate Change Cambridge University Press, Cambridge UK and New York NY USA, p 847 Available at: http://www.ipcc.ch/publications_and_data/ar4/wg1/en/ch11.html

Dai A (2006) Precipitation Characteristics in Eighteen Coupled Climate Models. J. Climate 19:4605-4630

Faurès J-M et al (2007) Reinventing Irrigation. In Molden D (ed.), Water for Food Water for Life: A Comprehensive Assessment of Water Management in Agriculture. Earthscan, London and International Water Management Institute, Colombo p 353

Graf WL (1999) Dam nation: A geographic census of American dams and their large-scale hydrologic impacts. Water Resources Research 35(4):1305-1311 
Groves DG, Yates D, Tebaldi C (2008a) Developing and applying uncertain global climate change projections for regional water management planning. Water Resources Research 44:W12413

Groves DG, Lempert R, Knopman D, Berry S (2008b) Preparing for an Uncertain Future Climate in the Inland Empire - Identifying Robust Water Management Strategies, RAND Corporation, Santa Monica, CA. Available at: http://www.rand.org/content/dam/rand/pubs/documented_briefings/2008/RAND_DB5 50.pdf

IISD (International Institute for Sustainable Development) (2012) CRiSTAL User's Manual Version 5: Community-based Risk Screening Tool - Adaptation and Livelihoods. Winnepeg, International Institute for Sustainable Development. Accessed 9/20/13 at: http://www.iisd.org/pdf/2012/cristal_user_manual_v5_2012.pdf

Hallegatte S (2009) Strategies to adapt to an uncertain climate change. Global Environmental Change 19:240-247

Kundezewicz ZW, Mata LJ et al (2007) Freshwater Resources and their Management. In: Parry et al (eds) Climate Change 2007: Impacts, Adaptation and Vulnerability. Contribution of Working Group II to the Fourth Assessment Report of the Intergovernmental Panel on Climate Change. Cambridge University Press, Cambridge, p 173. Available at: http://www.ipcc-wg2.gov/AR4/website/03.pdf

Lenderink G, Van Meijgaard E (2008) Increase in hourly precipitation extremes beyond expectations from temperature changes, Nature Geoscience 1:511-514. Published online 20 July 2008; doi:10.1038/ngeo262, at: http://www.nature.com/ngeo/journal/v1/n8/pdf/ngeo262.pdf 
Major, DC, O’Grady M. (2010) Adaptation Assessment Guidebook. Annals of the New York Academy of Sciences 1196:229-292.

Meinzen-Dick R (2007) Beyond panaceas in water institutions. Proceedings of the National Academy of Sciences of the United States 104:15200-15205

Molden, D (ed.) (2007) Water for Food Water for Life: A Comprehensive Assessment of Water Management in Agriculture. Earthscan, London and International Water Management Institute, Colombo

National Research Council (2009) Informing Decisions in a Changing Climate. National Academy Press, Washington D.C.

NDWAC (National Drinking Water Advisory Council) (2011) Climate Ready Water Utilities, Final Report to the U.S. Environmental Protection Agency. Accessed 9/19/13 at: http://water.epa.gov/drink/ndwac/climatechange/upload/CRWU-NDWAC-Final$\underline{\text { Report-12-09-10-2.pdf }}$

NPCC (New York City Panel on Climate Change) (2010) Climate Change Adaptation in New York City: Building a Risk Management Response: New York City Panel on Climate Change 2010 Report, Annals of the New York Academy of Sciences 1196:1-354

Ostrom E (2007) A diagnostic approach for going beyond panaceas. Proceedings of the National Academy of Sciences of the United States 104:15181-15187.

Palmer MA (2010) Water resources: Beyond infrastructure. Nature 467:534-535.

Pearce F (2006) When the Rivers Run Dry: Water - The Defining Crisis of the Twenty-first Century. Beacon Press, Boston.

Postel, S, Richter B (2003) Rivers for Life: Managing Water for People and Nature. Island Press, Washington, D.C. 
Rosenzweig, C et al (eds.) (2011) Responding to Climate Change in New York State: The ClimAID Integrated Assessment for Effective Climate Change Adaptation. Synthesis Report. New York State Energy Research and Development Authority (NYSERDA), Albany NY

The Guardian (2010) Yemen threatens to chew itself to death over thirst for narcotic qat plant, 26 February. http://www.guardian.co.uk/environment/2010/feb/26/yemen-qat-water-drought UNEP (2011) A Practical Framework for Planning Pro-Development Climate Policy, UNEP report, Scrieciu S, Bristow S, Puig D (lead authors), United Nations Environment Programme, online at http://www.mca4climate.info

UN-OCHA (2012) Humanitarian Bulletin: Yemen. Issue 04- 12 June 2012. United Nations Office for the Coordination of Humanitarian Affairs, www.unocha.org.

USEPA (United States Environmental Protection Agency) (2012) National Water Program 2012 Strategy: Response to Climate Change. USEPA Office of Water (4101M) EPA-850-K12-004. Accessed 9/ 19/13 at: http://water.epa.gov/scitech/climatechange/upload/epa_2012_climate_water_strategy full_report_final.pdf

Vörösmarty C et al (2010) Global threats to human water security and river biodiversity. Nature $467: 555-561$

Wilby RL, Dessai S (2010) Robust Adaptation to climate change. Weather 67:180-185.

World Bank (2010) Republic of Yemen: Assessing the Impacts of Climate Change and Variability on the Water and Agriculture Sectors, and the Policy Implications. Report No. 54196-YE. Sustainable Development Sector Department, Middle East and North Africa Region. World Bank, Washington D.C. 
World Commission on Dams (2000) Dams and Development: A New Framework for DecisionMaking. The Report of the World Commission on Dams. Earthscan Publications, London Yates D, Miller K (2011) Climate Change in Water Utility Planning: Decision Analytic Approaches. The Water Research Foundation, Denver 


\section{Figure Legends:}

Figure 1: The generic criteria tree of the MCA4climate methodological framework

Figure 2a: Dry Scenario: Option Profiles* (allocated scores) across all level 3criteria for U3 (urban demand management); R2 (incentives to adopt efficient irrigation technology) and BW3 (retiring land from irrigated agriculture). Based on an early version of the criteria tree.

Figure 2b: Mid Scenario: Option Profiles* (allocated scores) across all level 3criteria for U3, R2 and BW3. Based on an early version of the criteria tree.

*A high score is preferred on both input and output criteria (corresponding to a lower resource requirement on input criteria or a greater positive impact on output criteria).

Figure 3: Initial weights allocated to criteria across the tree (early version) and aggregated to the next level

Figure 4a: Efficiency plot showing Inputs vs Outputs, determined using initial criteria weights Figure 4b: Efficiency plot showing Inputs vs Outputs, determined using increased weight on Social impacts

In Figures 4a and 4b the two panels on the left show the criteria weights aggregated to level 2 of the criteria tree (these can be changed interactively to explore the impact on options' aggregate scores). The central panel shows the Option Profiles at level 1 of the tree (scores are aggregated to the level of Inputs and Outputs*). The Efficiency Plot (on the right) plots aggregate Output vs Input for each option with the dashed line highlighting the options that generate the highest Outputs in relation to their required Inputs.

* Note that higher aggregate values on both inputs and outputs are preferred (i.e. correspond to lower resource requirements and higher impacts) 


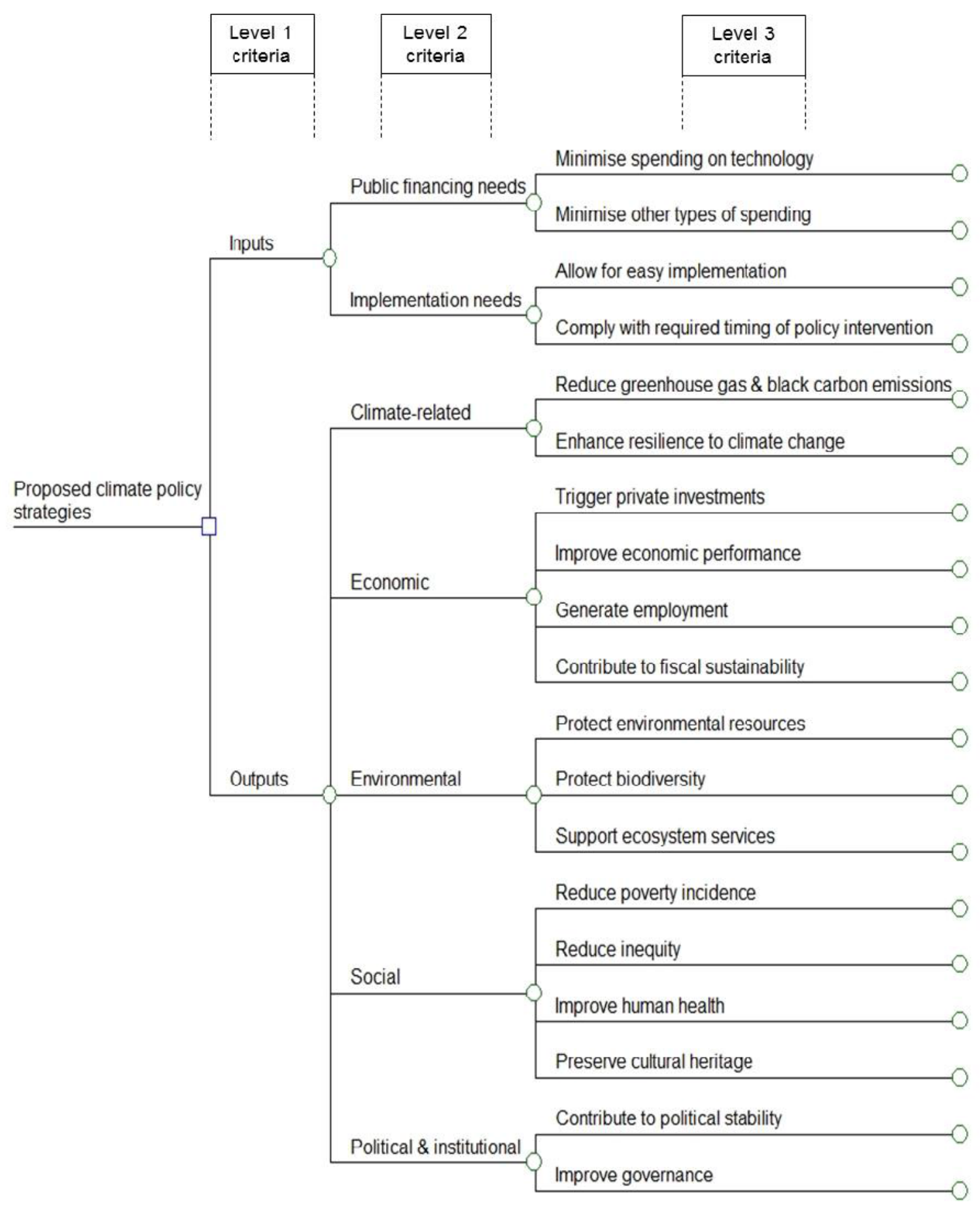

Fig 1 


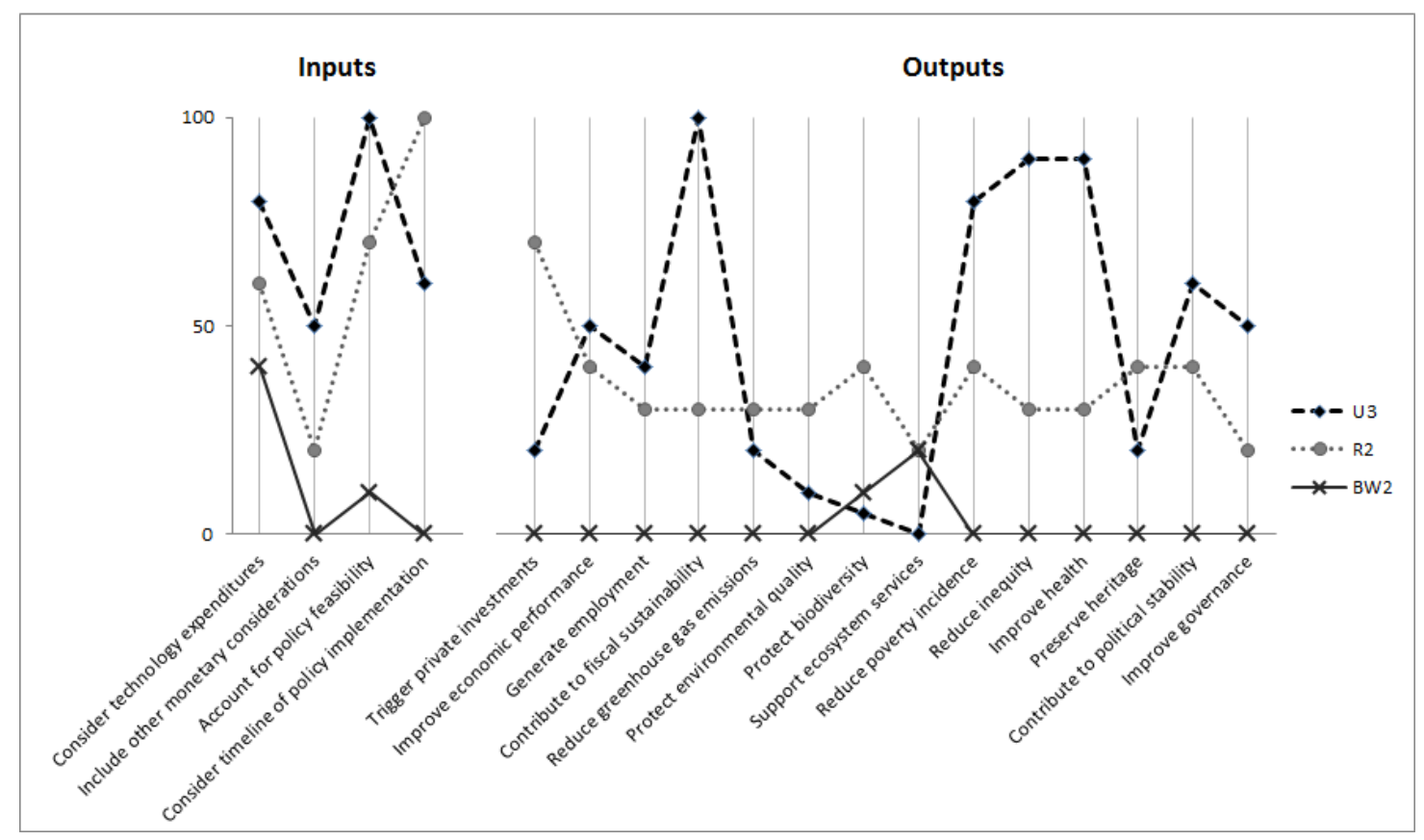

Fig 2a

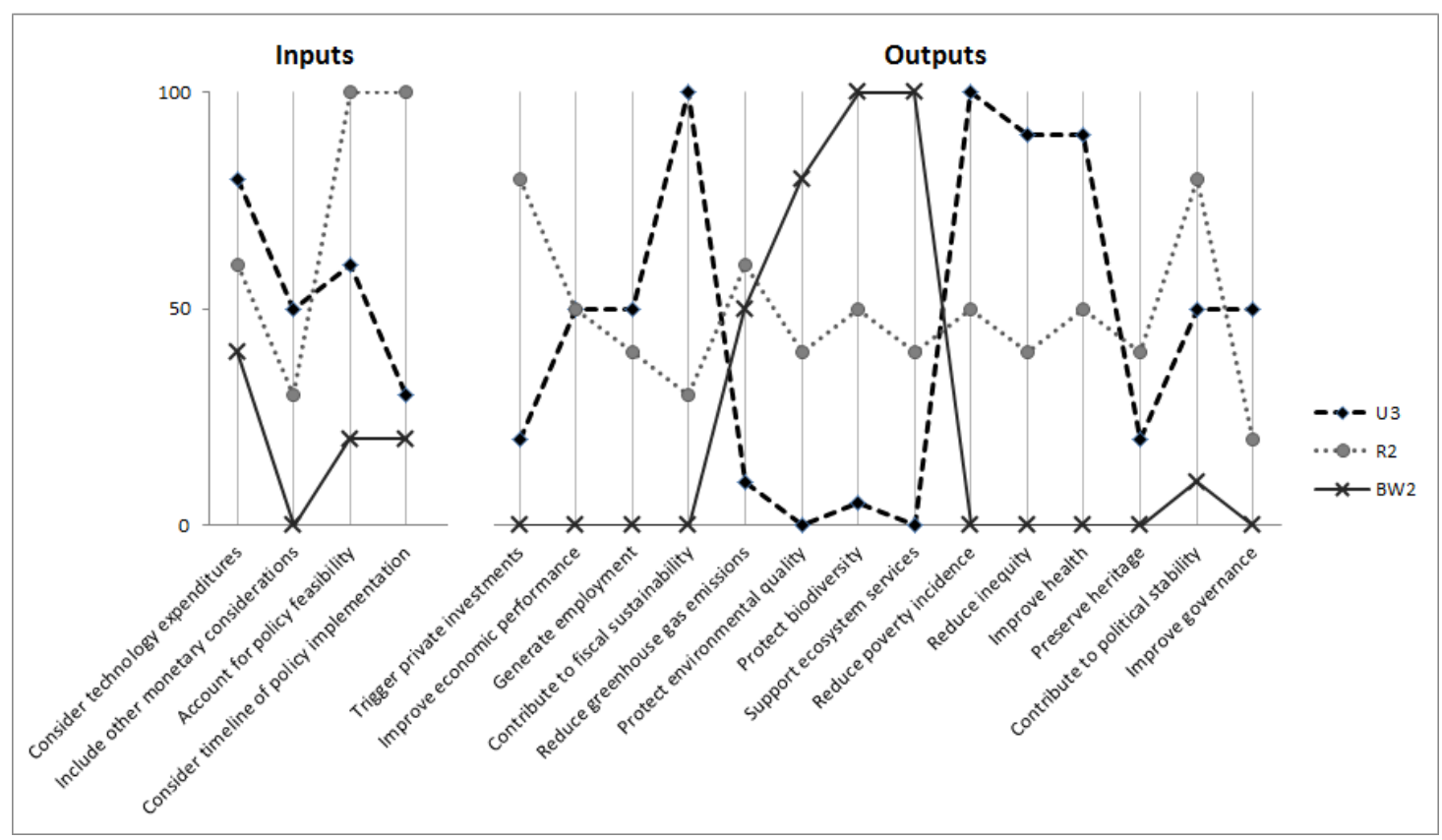

Fig 2b 

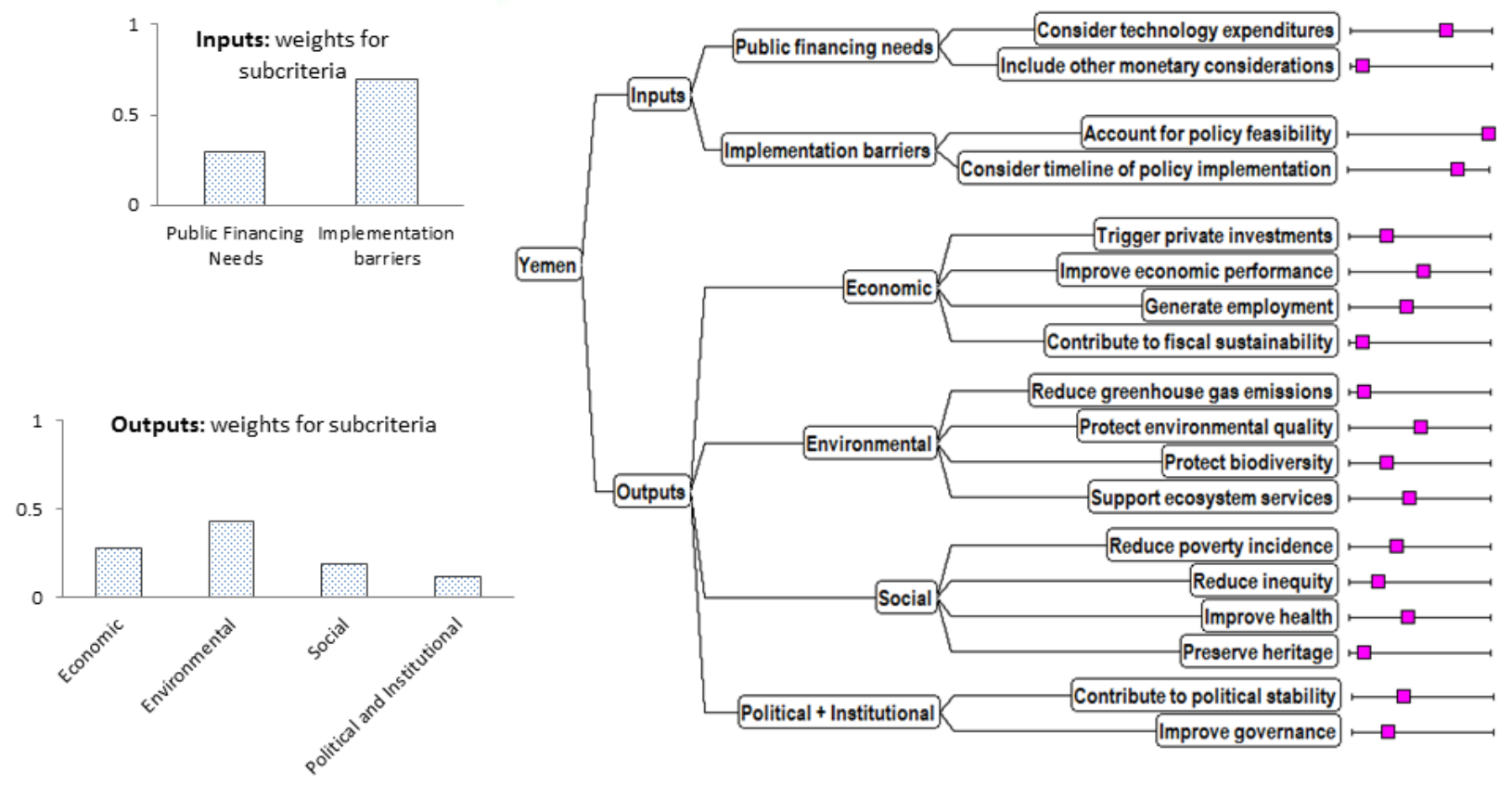

\section{Figure 3}



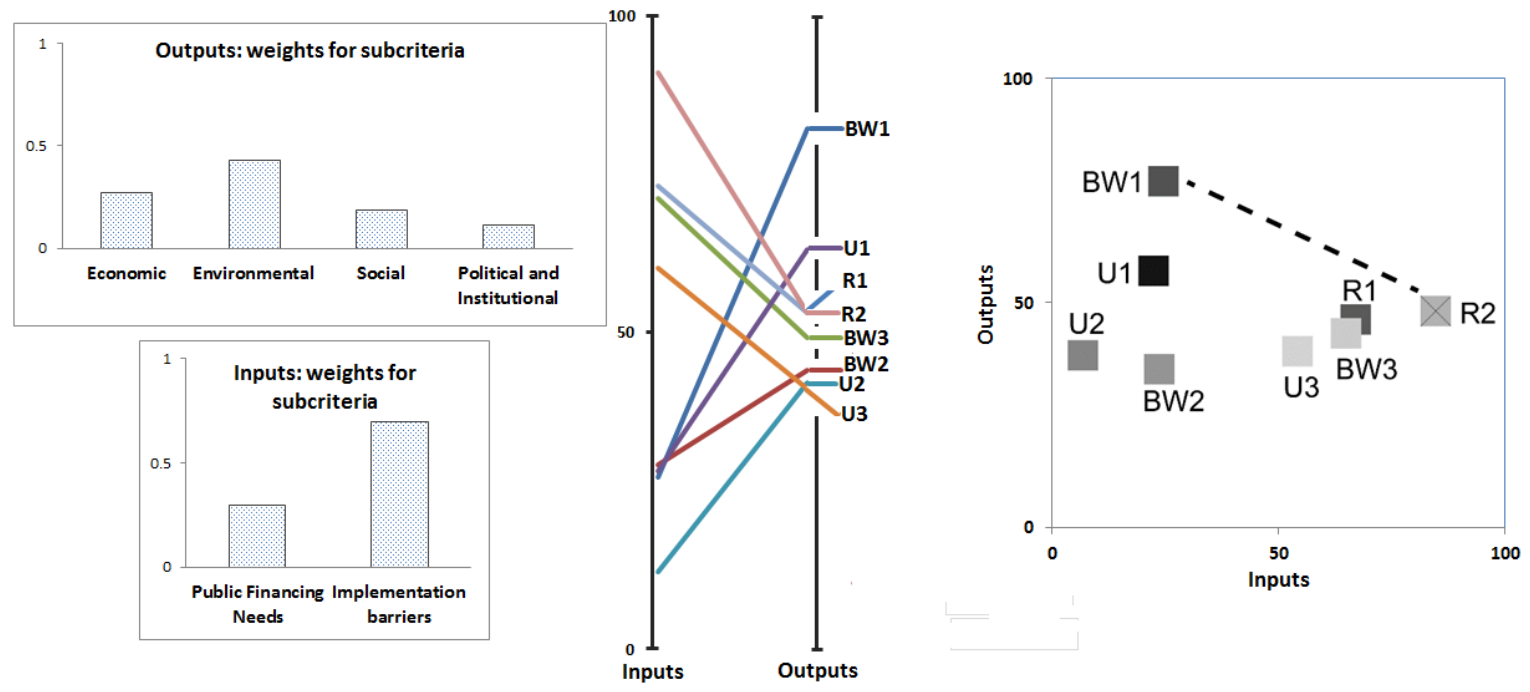

\section{Fig 4a}
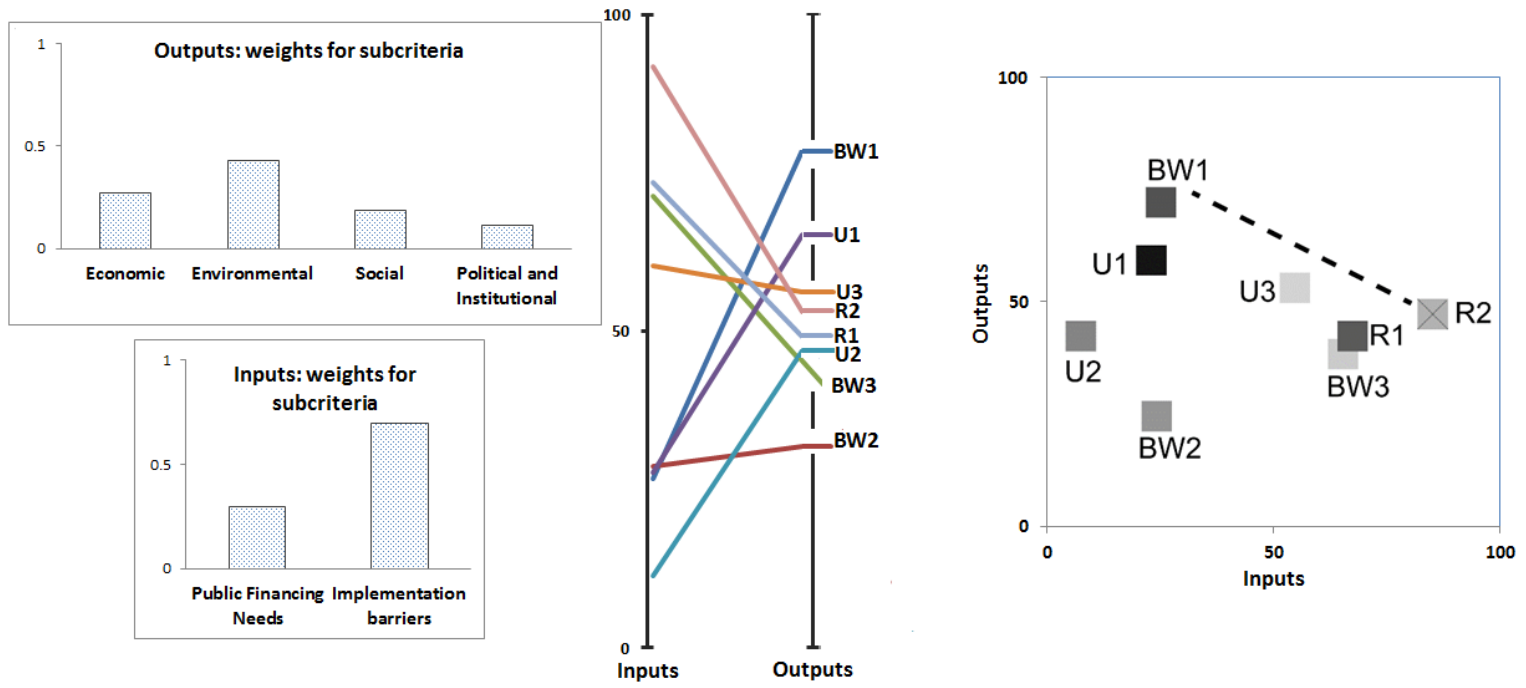

Fig 4b 
Table 1: Policy options to improve water management in the Sana'a Basin, Yemen

\section{Policy Description}

Basin-wide (BW)

BW1: Strengthen basin-

The most complex and comprehensive of the options considered.

wide water planning and governance

Accelerated implementation of the following reforms was assumed:

Establishment of a process for basin-wide determination of limits on total water use by area and type

Requirement for full coverage of irrigated land within water user associations (WUAs)

Enhanced powers and responsibilities of WUAs to implement and enforce limits on well-drilling and water extraction

Legal mechanisms for transfers of water extraction rights and land easements

BW2: Retire lands from agricultural use

Creation of a public program to purchase land currently used for irrigated agriculture and to return it to a natural state. A target of 25

$\%$ reduction (c.6 $000 \mathrm{ha}$ ) in irrigated hectares was assumed. The effectiveness of this option would depend heavily on implementation of other governance measures, because without those reforms, there would be nothing to keep other land-owners from expanding irrigation operations on other lands.

BW3: Integrate land and

A set of projects to augment groundwater recharge and limit water management

drawdown by instituting a low-cost loan or matching grant program to maintain and restore terraces for soil and water conservation, and build spate check dams and recharge basins.

\section{$\underline{\operatorname{Urban}(\mathrm{U})}$}

U1: Protect the quality

and usability of existing water resources

U2: Provide Desalinized sea-water to Sana'a

U3: Implement urban water demand management
Reverse the present trend of urban-source pollution of shallow groundwater resources, primarily from untreated sewerage, by improving sewerage and waste-water treatment systems and by providing other waste management services.

Install solar-powered desalination plants on the coast and use solar power to pump the water uphill to the Sana'a Basin. Assumes a 1 billion cubic meter/year plant and pipeline at a capital cost of USD $\$ 6$ billion with a cost of delivered water of USD \$1 per cubic meter.

Reform public water tariffs for the purpose of collecting sufficient funding for system improvements, including developing a system for metering, billing and revenue collection that would use increasing block rate pricing to keep lifeline water rates low while charging higher rates to households that use large amounts of water. It was assumed that this policy would provide enough revenue to pay for major system improvements that would allow all urban households to have access to safe, reliable public water supplies, although not necessarily in-home taps. 


\section{Rural (R)}

R1 Create incentives to promote efficient use of agricultural water.

Eliminate remaining subsidies on diesel, as well as the agricultural import restrictions that had helped to spur the race to exploit groundwater reserves for irrigated agriculture. It was assumed that the government would continue raising diesel prices to worldmarket levels, and would eliminate import restrictions/tariffs on fruits, vegetables and qat.

R2: Create incentives to Extend current programs aimed at increasing crop output and promote demand-side technology uptake. income per unit of irrigation water consumed (e.g. provide low-cost loans to install piped irrigation systems, mulching and similar investments to conserve water). It was assumed that the government would make these programs available to any willing farmer in the Sana'a Basin. It was also assumed that the policy would be implemented without any restrictions on eligibility or on the total extent of irrigated land in the basin. 